Research Article

Vivian Christopher Kapilima*

\title{
The Impact of Power and Power Relationships in the Public Policy Formulation Process: A Case Study of the Formulation Process of 2014 Tanzania's Education and Training Policy
}

https://doi.org/10.1515/openps-2020-0020

received June 4, 2020; accepted July 23, 2020.

\begin{abstract}
Power struggle among stakeholders in public policy formulation process is a common phenomenon in a state informed by democratic politics. The extent of its gravity could have positive or negative implication in policy legitimacy, ownership, and implementation processes. The formulation process of Tanzania's Education and Training Policy (ETP) of 2014 saw a substantial varied set of competing stakeholders. Each set of actors exerted a different amount of power, which subsequently impacted the policy process. Empirical data revealed that the process was dominated by government officials and few prominent as well as powerful Community-Based Organizations. Recommendations from such categories of stakeholders were likely to be included in the policy document, unlike those from the powerless, non-famous, and ordinary citizens. Besides, scarcity of resources and persuasion through arguments, which enter the category of politics of policy making process, coupled with opposing values and interests of policy actors were the main factors that determined powers over decision making. Therefore, this article suggests that a big enough budget should be provided to the entire policy formulation process, and a need to put, in place, effective power balancing mechanisms with a view to widen and deepen the level of stakeholders' participation in policy formulation process.
\end{abstract}

Keywords: Tanzania’s Education Policy; politics of policy making; power politics.

\section{Introduction}

\subsection{Background Information}

There have been long-standing philosophical traditions relating to the concept of power since the time of Plato, Aristle and Hobbes, to name but a few. Works of these thinkers serve as classic foundations of social sciences' power analysis approach of qualitative inquiry. In social sciences, power is a complex term. Normatively, it is conceived as the capacity to affect interests of the agents. Some scientists emphasize the role of potential conflicts of interests in defining power relations. Others take legitimacy and consensus about norms as the basis. There is also a social view, which stresses that power must rest with agents or with social structures (Creig, 2000, p. 703). This paper takes the first view of conflict of interests in analyzing power relations. Hobbes observed that power has potential contributions to human life by assisting, enabling or impending human beings in living and acting as they wish (Dunn, 2010, p. 417). Public policies are instruments of fulfilling this assertive objective by translating an agreed set of ideas into actions. As already presented, power plays a central role in human social life, and it is the great determinant of every human being's action. Thus, given this important role, issues of power and power relations should not be overlooked or isolated from the task of analyzing the public policy formulation process, the process, which is contentious by nature, as it involves a wide set

*Corresponding author: Vivian Christopher Kapilima, The Mwalimu Nyerere Memorial Academy, Dar es Salaam, United Republic of Tanzania, E-mail: kapilimavivian@yahoo.com 
of actors, some of them are non-officials, while others are officials from different levels of government system. Each set of actors exerts a different amount of power to influence on the policy formulation process. It is for this reason that some actors appear to be more powerful than others, while others, mostly non-officials, seem to be relatively powerless or moderately influential in the policy formulation process. Such power differences, among key policy actors, seem to have impacted on formulation processes of the past Tanzania's Education and Training Policy (ETP, 1995) and the current ETP (2014). The development of the latter was an outcome of expiry and hence, revocation of the ETP (1995), Vocational Education and Training Policy (1996), National Higher Education Policy (1999), and the Information and Communication Technology (ICT) Policy for Basic Education (2007). These education policies were seen to be outdated and they were unable to respond to emerging issues in the education sector in a dynamic world.

Formulation of ETP (2014) was triggered by both internal/domestic and external factors and challenges. It was revealed that the policy cycle approach, which emerged from the work of Harold Lasswell (Hallacher, 2005, p. 11), was employed in formulating the policy. As alluded to in this section, the policy formulation process was contentious in nature, as it involved a wide set of actors, each of with their own agendas and interests - struggling over the process. Thus, such a state of affairs pointed to the need to adopt the social sciences' power analysis approach in addressing the impact of power, and power relations in the formulation process of ETP of 2014. Specifically, the study sought to identify stakeholders who were powerful, and dominated the policy formulation process; factors that determined power and its application in policy construction; the way power was exercised; and the power locus, that is, where did power lay during policy formulation process?

\subsection{Objectives of the Study}

As previously stated, the main objective of the study was to examine the impact of power and power relationships in formulation process of 2014 Tanzania's Education and Training Policy. Specifically, the study sought to identify stakeholders who were powerful, and dominated the policy formulation process; to assess factors that determined power and its application in policy construction; to assess the way power was exercised; and to determine the power locus, that is, where did power lay during policy formulation process?

\section{Theoretical Framework}

The fact that public policy formulation is a contentious process, characterized by interested actors struggling over ideas (Rochefort \& Cobb, 1994; Fischer et al., 2007, p. 84), means that it is imperative to adopt two opposing theoretical frameworks of power distribution in the society - the pluralist and the elitist. These theoretical constructs describe what is important to look at, to understand and explain the nature of power relationships observed in stakeholders' participation during the formulation of ETP (2014). Pluralist was founded by the following scholars, James Madison, Alexis de Tocqueville, and Dahl Robert (Howes et al., 2004, p. 4; Blockland, 2016, p. 25). Elitist is a variant of Marxist perspectives of state and its origins lie mostly clearly from the works of Gaetano Mosca, Vilfredo Pareto, and Robert Michels (Leicht \& Jenkins, 2009, p. 161). Pluralist arguments emphasize on wide distribution of power and inclusion of diverse sets of participants and interests, and the importance of willingness to work on conflict resolution during policy formulation process.

A lack of majority of people/entities' participation in education public policy formulation could well be construed from an elitist theoretical perspective. Accordingly, the theoretical stance is a manifestation of disfavored power structures and administrative systems of the state. From a political science point of view, disfavored power structures entail a way in which power and authority are not equally distributed between people in the government system. In this arrangement, the few powerful government mandarins will dictate the policy making process, while the rest will be passive, accept or add little inputs into the process. Therefore, in this study, presented theoretical constructs were instrumental in providing answers to the research questions, such as which types of stakeholders were involved in formulating the ETP (2014) education policy paper in Tanzania? Who dominated the policy formulation process? How was power exercised? Finally, what are the impacts of unequal power relationships in the policy formulation process? 


\section{Materials and Methods}

\subsection{Research Design}

The stated objectives of the study compelled the use of qualitative research approach through exploratory research strategy. This was informed by social constructivist paradigm, which conceives reality as a result of social construction (Berger \& Luckmann, 1967, p.13). The fact that in social sciences, power is a socially constructed phenomenon, the research approach was helpful in understanding the social context involved the exercise of power in formulating the 2014 Tanzania’s Education and Training Policy (ETP).

\subsection{Study Area}

The formulation process of 2014 Tanzania's Education and Training Policy was selected to be a case study. That decision was due to the existence of little empirical evidence on the manner the policy was formulated and specifically on impacts of power and power relationships in the policy formulation process. Many studies on Tanzania's Education and Training Policies concentrated on policy contents, policy implementation process, and policy outcomes, and not on policy formulation process, particularly on how power relationships between policy actors affect policy formulation process, policy outputs and outcomes. Therefore, this study was designed to fill that gap. Dar es Salaam and Dodoma cities of Tanzania were selected as study areas because of the availability of a wide set of policy actors, coupled with the fact that many education stakeholders, both government and non-government officials who were involved in crafting the policy reside in those cities. In Dar es Salaam city, the study was conducted in four districts, namely, Ilala, Kinondoni, Ubungo, and Temeke; whereas, in Dodoma city, it was conducted at the Ministry of Education, Science, Technology and Vocational Training.

\subsection{Sample Size}

Sample size was determined by qualitative method of saturation whereby the researcher established a stopping rule and continued to sample until the rule was satisfied. In other words, until the additional research elements did not provide new information on the issue under investigation (see Daniel, 2011, p. 247). Thus, a total number of 17 research participants were interviewed, as shown in Table 1.

Table 1: Type of education stakeholders and the number of informants who participated in the study.

\begin{tabular}{lll}
\hline SN. & Education stakeholders/research participants & Number of research participants \\
\hline 1 & Ministry of Education, Science, Technology and Vocational Training & 2 \\
2 & Tanzania Institute of Education & 1 \\
3 & Dar es Salaam District education offices & 2 \\
4 & Tanzania Teachers' Union & 1 \\
5 & University of Dar es Salaam, School of Education & 3 \\
6 & HakiElimu and Tanzania Education Network/Mtandao wa Elimu Tanzania & 3 \\
7 & Representatives of private owners of secondary schools and colleges & 2 \\
8 & Christian Social Services Commission & 3 \\
\hline
\end{tabular}

Source: Researcher's own tabulation 


\subsection{Sampling procedures}

This study employed purposive and snowball sampling techniques in getting key informants who could articulate their perceptual experiences on the formulation process of 2014 Tanzania's Education and Training Policy. Moreover, such techniques were chosen because of their flexibility in terms of application. The purposive sampling technique is based on the researcher's own judgment about which units are more representative or useful than others (Rubin \& Babbie, 2009, p. 148). Therefore, the researcher's judgment criteria that were used to obtain key informants included: age (the adults), gender (both males and females), awareness of the 2014 Tanzania's Education and Training Policy, occupation (for example, government education officers, headmasters, teachers, academia, and representatives of local and international NGOs; and representatives of CBOs). Snowball sampling technique was applied because it was not easy to identify and access directly key education stakeholders who participated in the policy formulation process. The technique was applied in the following manner: First, potential subjects participated in the formulation of policy were identified, and they were asked to get others who also participated in the policy formulation process.

\subsection{Data Collection Methods}

In-depth face to face interview was the major method employed in data collection process. Semi-structured interview questions were employed for the study. To confirm information collected from interviews, focus group discussions were carried out through two groups. One group constituted seven government education quality assurance officers, and another was formed by six representatives of education based civil society organizations in Dar es Salaam city.

\subsection{Data Analysis Plan}

Collected data were sorted and arranged in thematic areas. Then they were transcribed and they were subjected to content analysis.

\section{Results and discussions}

This section presents results and discussions. It starts with mapping potential stakeholders who were involved in formulating the 2014 Tanzania's Education and Training Policy, followed by stakeholders who dominated the policy formulation process and impacts, factors that determined exercise of power as well as the power locus during the policy formulation process.

\subsection{Mapping policy stakeholders}

The goal of every stakeholder's mapping process is to develop a useful list of stakeholders, to analyze their key characteristics and present information in a way to determine groups with interest in a project, and groups typically included or excluded from the project (see Bourne \& Weaver, 2010). Therefore, based on the objective of this work, it is imperative to classify education stakeholders who participated in the project of formulating the ETP (2014). However, due to several limitations faced during data collection process, some stakeholders were not included in the classification list, and the fact that research is an endless process of acquiring knowledge (Reid et al., 2013, p. 84). Thus, future studies may expand the list by uncovering other kinds of stakeholders who participated in the policy process.

In this study, it was revealed that the approach that was employed in the policy formulation process was participatory, mainly based on "representation" whereby a particular group of key stakeholders was invited to provide views on behalf of its members. Such representation approach of stakeholders' views is essentially pluralist (see Rechtschaffen \& Gauna, 2002, p. 125). Therefore, based on a use of representation approach, two main kinds of 
stakeholders were mapped. They included local and international stakeholders. The local stakeholders fall into the following five categories: the government; private stakeholders; heads of secondary schools, colleges and universities; students' organizations in higher learning institutions; and civil society organizations.

In the analysis, private stakeholders are not individuals, but groups of stakeholders who own private profitmaking institutions and organizations. For example, in the education sector, such group was represented by Tanzania Association of Managers and Owners of Non-governmental Schools and Colleges (TAMONGSCO). The government, as a policy initiator, had a number of stakeholders from both central and local administration levels. Mainly, they were education officials in the ministry and local governments. Some identified stakeholders, and who are independent, but fall under this category of stakeholders included the Tanzania Institute of Education, National Council for Technical Education (NACTE), National Examinations Council of Tanzania (NECTA), Vocational Education and Training Authority (VETA), and Higher Education Students' Loan Board (HESLB), just to mention in a few.

Also, there were two groups of stakeholders under the category of heads of schools, colleges and universities that were involved in the said policy formulation process. During the policy formulation process, views from heads of secondary schools were represented by their association, under the name Tanzania Heads of Secondary Schools Association (TAHOSSA), while views from Vice Chancellors, Principals, and Provosts of colleges and universities were represented by their committee, the Committee of Vice Chancellors, Principals and Provosts in Tanzania (CVCPT). The fourth category of education stakeholders included students in the higher learning education institutions. This group, according to the survey, was represented by their organization, the Tanzania Higher Learning Institutions Students' Organizations (TAHLISO).

The last category of local stakeholders, according to informants of this study, was critical in influencing and pushing development of ETP (2014), included community and civil society organizations. Under this category, three kinds of stakeholders were found. They included non-profit making education networks and organizations; faith-based entities, but private owners of education institutions; and trade unions. Non-profit making education networks and organizations included Tanzania Education Network/Mtandao wa Elimu Tanzania (Ten/Met), HakiElimu, and Twaweza/Uwezo, among others. The faith-based entities encompassed Christian Social Services Commission (CSSC), and the National Muslim Council of Tanzania (NMCT). Lastly, the trade union-based involved Tanzania Teachers' Union (TTU).

The second type of education stakeholders included International Development Partners (IDPs). With regard to involvement of this group of actors in policy formulation, one of the interviewed stakeholders in this study held the view that,

"Despite the IDPs being the important kind of stakeholders that have to be included in the formulation of education policy because they provide their experience, expertise and financing education projects but they should not be highly involved in the process because policy issues capture national interests. Indeed, public policy is a national document that has to be developed through public consensus process, as it reflects the overall demands of the public."

On top of that, another informant held views that; "international organizations are potentially powerful and can shape the policy agenda to favor their interests, if they are given a prominent role in the formulation of education policies."

This informant's observation is similar to that disclosed by Millar (2009, p.121), Bartlett and colleagues (1995, p. 161) and Inocencio (2014, p. 78) who asserted that international organizations can determine state's definition of their interests through their role as providers of information and through the larger role they play in setting agenda for international discussion as well as negation. Such organizations influence government policy by engaging in persuasion whereby the government may choose to respond to the international organization's signals by adjusting their policies (Fang \& Stone, 2012, p 7). However, if the government would not take and maintain the initiative in the process of designing its policy, by making it the responsibility of only senior ministry officials, it may leave a vacuum that would make the impact of international organizations equally stronger thereby diminishing the bureaucrats' policy space in policy making process (Buchert, 1997, p. 55; Caroll \& Common, 2013).

Likewise, one of the government officials from the current Ministry of Education, Science, Technology and Vocational Training (MoESTVT) disclosed that, "the international development donors and agencies were minimally involved in the formulation of ETP (2014) when compared to ETP (1995). They were especially minimally involved in the initial stages of opinion giving. Other stages, like policy drafting can be confidential, and due to the fact that a policy is a national document, few international organizations were involved in the process. Some organizations 
such as Campaign for Female Education (CAMFED) and Plan International addressed gender issues and advocated for education rights for female students." The issue of confidentiality, which was linked to minimum involvement of international development donors in policy formulation, was strongly supported by Todress (1991) who asserted that, "confidentiality is one of the key issues that should be continually considered in policy making process. Policy making actors are expected not only to help develop policy but also to enforce the regulations that govern them in the course of formulating policy." Such regulations may include maintaining secrecy and confidentiality on the category of confidential government information to embrace a variety of classes of documents, whose disclosure, while not harmful to the policy decision-making process or integrity of the state, could injure a variety of individual or sectional interests, including certain government interests (Robertson, 1978, p. 6).

\subsection{Stakeholders who were powerful, and dominated the policy formulation process}

The study found out that power and power relations significantly affected the formulation of education policy papers in Tanzania. However, the manner in which such effects prevailed differed from one policy to another. For example, it was mentioned by Buchert (1997, p. 50) that the formulation process of Tanzania's Education and Training Policy (ETP) of 1995 was largely dominated by top government officials, few educationists, international aid agencies, and some academics from the University of Dar es Salaam. Such a power structure was unequal because the policy process was not inclusive in the sense that even headmasters and the wider public were not part of the process. Therefore, with such representation, it is clear that the ETP of 1995 formulation process was dominated by a few prominent and powerful stakeholders.

Contrary to the ETP of 1995, formulation of the ETP of 2014 pertaining to level of power relations was relatively better in the sense that consultations were broader than in the previous policy formulation process. Even so, some recommendations from some stakeholders were not included in the final policy version. The exclusion of such recommendations is manifestation of power struggles among policy actors, and as expected, recommendations from the prominent as well as powerful stakeholders were likely to be taken on board, rather than those of the powerless, infamous, and ordinary citizens. In their study, Göksu and Bilgiç (2003) concluded that interest groups who are powerful and use appropriate methods have great effect on policy decision mechanism. The current study was informed that the policy process was dominated by government officials and few prominent as well as powerful CBOs in Dar es Salaam city. Such an uneven distribution of powers among individuals and groups may lead to policy contents being decided in certain ways (Johnson, 2014, p. 150). It could have a significant impact on policy legitimacy, ownership, and implementation processes. The group less involved or completely omitted from the policy process would claim to have no policy ownership and pose legitimate reasons to oppose a contested policy (see Lynn, 2005, p. 273). Consequently, that may have the effect of hindering the capacity of administration to implement policy decisions thereby undermining supposed advantages of decisiveness attributable to a system by a single policy player (Elgie \& Moestrup, 2008, p. 219).

Furthermore, the study found out that although stakeholders were acknowledged to have been involved in the formulation process of the ETP of 2014 so that power and power relations had implications at all stages of policy formulation. This view seems to be supported by the field interviews. According to one of interviewees, "the design and coverage of the survey for data collection in constructing the ETP (2014) was under the decision of few influential policy actors, that is why, some stakeholders and some policy alternatives that were recommended were left out in the policy process.” Another interviewee argued that,

"not only power and power relationships determined the kind of stakeholders to be involved in the policy formulation, but also at what stage of policy formulation the selected stakeholders were to be involved. Hence, this was one of the reasons for omission of some stakeholders at some stages of formulating the policy."

From the elitist theoretical perspective, it was revealed that public policy is determined by the demands and actions of the ruling elite (Gul, 2009, p. 4), the relatively small number of people who control decisions in the fields of economy, society and government. Such individuals exercise their powers through superior bargaining resources, an aspect, which is crucial for defeating any powerless group, and through mobilization of bias, which is used to create barriers to exclude people from decision-making arenas (Gaventa, 1980). Therefore, in this way, it is possible for some stakeholders to be omitted at some stages of policy formulation process, a phenomenon that could have a significant impact on policy ownership, legitimacy, and implementation process, as already submitted in this paper. 


\title{
4.3 Factors that determined exercise of power in policy construction
}

Power relationships or the exercise of power in a social interaction process like in a policy making process is worthy of approval and depends on so many factors (Scott, 1994, p. 317). For instance, Russell (1999, p. 2) mentioned about resources and control of those resources. Notwithstanding, the exercise of power is also attributed to persuasion through arguments at different stages of policy making process. Likewise, the present study revealed two determinants of power exercise, availability of resources and persuasion through arguments, which enter the category of politics of policy making process, coupled with opposing values and interests of policy actors. Both factors determined the exercise of power during formulation of ETP of 2014. With respect to availability resources, one of the government education officials asserted that,

\begin{abstract}
"Lack of enough resources, both financial and human, forced the policy making authorities to dictate the nature of policy formulation process. In due regard, the process was, to some extent, selective of stakeholders' involvement and limited in terms of country's coverage. Moreover, lack of enough resources hindered the policy making authorities from considering policy alternatives, which would have otherwise not matched with available limited resources. Hence, it was necessary for these authorities to exclude some of the stakeholders' recommendations in the final policy document.”
\end{abstract}

Similar responses were provided by another interviewee who expressed that,

"Power and authority had no negative impact on formulation of ETP of 2014 but rather, the problem was on the budget allocated to the education sector. The sector's budget was not enough. Therefore, it was important for policy makers to be selective in collecting and prioritizing policy recommendations."

From the interviewees' viewpoints, it is clear that there was a lack of resources/constraints for budget choices in policy construction, which consequently limited decisions on policy alternatives to solve the problem. With an adequate budget, the chances for policy makers to influence on sound policy decision-making process become good. A sound policy decision will always approve what, in light of ascertainable scientific facts, can be expected to be an enhancement to what society regards as 'good life' (Jotterand \& Dubljevic, 2016, p. 94). The issue of prioritizing policy recommendations as stated by the interviewees was due to an inadequate budget allocated to the education sector. However, the chance for the problem being given high priority in policy-making forum is markedly enhanced if the problem is perceived to have involved potentially catastrophic effects to people and property (Ruch, 1991, p. 130). Thus, the government would take away resources from other issues and reallocate to the present policy problem, which has appeared particularly in an accentuated form (Castaneda et al., 2018, p.14).

Likewise, issues of politics of policy making were also raised by some interviewees among determinants of the power exercise during policy formulation process. Politics of policy making entail a kind of policy process shaped by competing narratives informed by divergent interests and articulated by different discourse coalition based on power as well as their claims of knowledge. They exist as a rational technical solution as well as a political instrument for producing, contesting, implementing, and reforming public policies (Asthana, 2009, p. 153). However, characteristically, the process has been seen to be very complicated and the understanding of why this or that policy option did or did not get accepted must be able to handle that complexity (Marmor, 2017). Thus, in examining the exercise of power in politics of policy making, during ETP (2014) formulation process, one of the academics from the University of Dar es Salaam, who participated at some stages of policy formulation process informed the study that,

\footnotetext{
"Obviously, those who are in power, mostly the state political-bureaucrats, are the ones who are in the position to decide what should be included in the policy document. These state actors have their varied values and interests, and are the ones who endorse and authorize the policy to be implemented. This being the case, policy makers find themselves forced to incorporate views and opinions of politicalbureaucrats in the policy document in order for the document to be accepted and authorized for implementation.”
}

Although interviewed stakeholders pointed out the negative aspects of power relations in ETP (2014) formulation process, they did not mention anything about its positive side. In such a relationship, the government was identified as a "policy-cooking agency," while non-government education policy actors were solely characterized as "opinion providers." This view was further elaborated by one of interviewees, who claimed that, "What was going on in the 
final stage of producing ETP (2014) after we have provided our views, was not known. We only found that some of our recommendations were not included in the final policy document."

Thus, the interviewee's assertion is a clear indication that the government seemed to conceal the final stage of policy making process from some stakeholders. However, it has to be noted that if the particular group of stakeholders is not given the opportunity to be part of the group that makes final policy decisions, it does not mean that they are less important policy actors. Notwithstanding, and according to one of the interviewees, 'it is difficult for all stakeholders to be involved at all stages of policy making process. Rather, there is a division of stakeholders' involvement in the process. Some will participate in the problem identification stage, and others may participate in the stage of formulating policy options.' The stage like policy adoption decision-making, which takes such forms as enactment of legislation or issuance of an executive order (Anderson, 2010, p. 125), involves fewer actors as it is normally excludes nearly all non-state actors. Only those politicians, judges, and government officials authorized to make decisions in a particular policy area, adopt, modify, or reject a preferred policy alternative (Zafarullah \& Huque, 2012, p. 232). Therefore, in this arrangement, it is possible for some non-state policy participants to claim for exclusion of their recommendations in the final stage of policy making process, like in the case narrated by the interviewed stakeholders.

\title{
4.4 The way power was exercised during policy formulation process
}

The exercise of power is evident in every sphere of social interaction. In policy-making discourse, it entails competition for influence and ability to exert policy agendas including alternatives by one individual or institution over another (Andrea \& Hemant, 2013). Focusing on the exercise of power assists in defining existing relationships among actors, how power is put into effect with its impacts. One of the education officials presented the case of cabinet that depicts the actual manner in which power was exercised during the ETP (2014) formulation process. The official asserted that,

\footnotetext{
"It is obvious that decision-makers come in the final stages of policy making process when the document has already been crafted and ready to be reviewed and passed by the cabinet. It is at that stage, where we witnessed the exercise of power and its impacts, since it is the cabinet, which has the power and authority to decide what should be in the document and what should not. For example, such a case happened during the discussion on the medium of instruction to be used in schools, and on the issue of allowing pregnant students to return to school after delivery. During policy formulation, stakeholders recommended use of single medium of instruction. However, the cabinet decided on use of both, English and Kiswahili language. Likewise, the cabinet was against the idea of pregnant students going back to school."
}

One of the interviewees, who condoned exercise of power in the construction of that policy, claimed that,

\begin{abstract}
"the issue of unequal power relationships between government and non-government policy actors, which appeared during the development of ETP (2014) is a common phenomenon, since it is true that, the government really deserved that special power because it is an entity responsible for designing and initiating public policies; it is the main implementer of the public policy, hence, it has to be selective in its promises and in collecting stakeholders' policy alternatives to be implemented; and besides that, it is an entity which adopts the policy and grants it the legal power to enable its effective implementation.”
\end{abstract}

Therefore, according to the quoted interviewee, unlike other stakeholders, the government underscored the right of being dominant stakeholder in the policy formulation process.

\subsection{Where did power lie during policy construction process?}

Another issue came to the fore, with respect to power relation and its impacts on policy formulation, "power locus," that is, where power lay or concentrated during the policy formulation process. It was submitted by Gul (2009, p. 1) that, "who gains access to the policy agenda depends on where power is concentrated." Results from this study revealed that the government wielded powers, but also it seems that there were other stakeholders who were powerful and influential in comparison to others. The reasons for the power differences, among others, were a result of nature of stakeholders' analysis conducted to identify key stakeholders who were to be involved in the policy formulation process. 
Although the researchers do not want to conclude that the nature of stakeholders' analysis was subjective or biased, it is argued that it brought about only the very famous and powerful stakeholders, mostly the education advocacy CSOs together with prominent faith-based and non faith-based private owners of schools and colleges. Furthermore, because of their varied positions, such stakeholders were given a special forum to present their concerns, and had the opportunity to present their recommendations directly to the policy making task force, since they were members of the survey team for the formulation of ETP of 2014. Besides, it was revealed that there are some groups of non-government stakeholders who were powerful to the extent that they were given position in one of the education sector technical teams of the Ministry of Education, for them to provide expertise opinion on education issues. Therefore, unlike other nonprominent stakeholders, the recommendations from the group and other groups of powerful stakeholders were easily accepted by the policy making team, and they were also incorporated in the ETP of 2014. Under such circumstances, one of the interviewees argued that, "the best practice should have constituted a joint committee composed of stakeholders from both the government and non-government sectors. The joint committee should have been the final decision maker of the policy." This is necessary as a way of reducing dominance of elites in the process. Moreover, the final decisionmakers on the policy options to be implemented should be drawn from such two groups of stakeholders. Adoption of such a modality will ensure that decisions would be objective and complaints from the public on unfair processes will be reduced or minimized.

\section{Conclusion and recommendations}

\subsection{Conclusion}

Results from this analytical study revealed that issues of power and power relationships significantly affected the formulation process of ETP of 2014 education policy paper. The nature of power relationships in sharing the policy process was good, to some extent, however, it was reported that some recommendations from some stakeholders were not included in the final policy version. Such exclusion of some recommendations in the policy process was manifestation of power struggles among contending policy actors. Recommendations from the powerful, famous and influential stakeholders were likely to be included in the policy document, unlike those from the powerless, infamous, and ordinary citizens.

Furthermore, power and power relationships had implications in all stages of policy formulation, and affected, to some extent, the extent of stakeholders' participation in the policy process. Besides, it was found that scarcity of resources and persuasion through arguments, which enter the category of politics of policy making process, coupled with opposing values and interests of policy actors, were the main factors that determined the decisions of policy making authorities and actually, their powers to affect the nature of ETP (2014) formulation process. Several interviewees cited the cabinet as the powerful policy actor in the government. Another issue that was exposed by analysis from this study is that of "power locus," that is, where power lay during policy construction. Though it was already mentioned that not only the government wielded powers, but also there were other few non-government education stakeholders who were powerful and influential in comparison with others in the policy formulation process. Such a power difference, among other reasons, was a result of the selective nature of the conducted stakeholders' analysis. Some stakeholders were given the special audience to present their concerns, and others had the opportunity to pass their recommendations to the policy making task force because they were in a survey team for ETP (2014) construction, and others had their representatives in one of the education sector technical teams of the Ministry of Education.

\subsection{Recommendations}

Therefore, based on findings from this study, the following are recommendations to foster equitable power relationships between different kinds of policy actors, whilst widening and deepening their participation level in the formulationprocess of education public policy: 
(i) Since the process of designing the formulation process of 2014 Education and Training Policy was determined, and, to some extent, it was influenced negatively by non-availability of enough resources, both financial and human, it is recommended that the government should provide adequate budgets before embarking on any policy-formulation activity. It is believed that adequate budgets are key in achieving better results and outcomes for a number of reasons. One, the number of stakeholders to be involved in the process would be scaled up. Two, it would facilitate production and dissemination of many policy drafts for circulation to stakeholders. Three, it would enable the task force to carry out representative dialogues, while broadening the country's geographic coverage.

(ii) There is a need to institute a mechanism to balance power relations among stakeholders during the policy formulation process. This is necessary as a way of reducing dominance of elites in the process. Therefore, it is important for a policy making task force to be composed of stakeholders from both the government and nongovernment sectors. Moreover, it is recommended that the final decisions on the policy options to be implemented should be drawn from these two groups of stakeholders. The adoption of such a modality will ensure that decisions would be objective and complaints from the public on unfair processes will be reduced. Another modality, for balancing power relationships among actors, is for the government to establish an independent quality assurance section, with its role of overseeing the process, monitoring and evaluation.

(iii) Although, academically, it is widely accepted that politics is part of public policy making, politicians should not dominate the process by bringing in their values and interests. In so doing, the policy process would be informed by opinion rather than being evidence-based process.

\section{References}

Anderson, J. (2010). Public Policy Making (7 $7^{\text {th }}$ ed.). Australia: Wadsworth, Cengage Learning.

Andrea, J. \& Hemant, R. (2013). Rethinking Power and Authority: Symbolic Violence and Subjectivity in Nepal's Terai Forests. Development and Change, 44 (1): 29-51.

Asthana, V. (2009). Water policy processes in India: Power and Resistance. London: Routledge.

Bartlett, R., Kurian, P., \& Malik, M., (Eds.). (1995). International organizations and Environmental Policy. USA: Greenwood Publishing Group Blockland, H. (2016). Pluralism, Democracy and Political Knowledge: Robert A. Dahl and his Critics on Modern Politics. USA: Routledge.

Berger, P., \& Luckmann, T. (1967). The Social Construction of Reality. A treatise in the Sociology of Knowledge. USA: Penguin Books, Bourne, L., \& Weaver, P. (2010). Construction stakeholder management. Wiley Online Library

Buchert, L. (1997). Education policy formulation in Tanzania: Coordination between the Government and International Aid Agencies. A report from the IWGE. International Institute for Educational Planning. PARIS: UNESCO:

Caroll, P., \& Common, R. (2013). Policy Transfer and Learning in Public Policy and Management: International Contexts, Content and Development. New York: Routledge.

Castaneda, G., Juarez, F., \& Guerrero, O. (2018). How do governments determine policy priorities? Studying development strategies through spillover networks. Journal of Economic behavior and Organizations, 154: 335- 361

Craig, E. (2000). Concise Routledge Encyclopedia of Philosophy. London: Routledge.

Dunn, J. (2010). The significance of Hobbes's conception of power, Critical Review of International Social and Political Philosophy, 13 (2-3): 417-433, DOI:

$10.1080 / 13698231003787844$

Daniel, J. (2011). Sampling Essentials: Practical Guidelines for Making Sampling Choices.

Los Angeles: SAGE.

Elgie, R., \& Moestrup, S. (2008). Semi-Presidentialism in Central and Eastern Europe. Manchester Manchester: University Press.

Fang, S., \& Stone, R. (2012). International organizations as Policy Advisers.

Available at: http://www.sas.rochester.edu/psc/stone/articles/FangandStone2012.pdf

Gaventa, J. (1980). Power and Powerlessness: Quiescence and Rebellion in an Appalachian Valley. Chicago: University of Chicago Press

Göksu, T., \& Bilgiç., V. (2003). Baskı Grupları ve Karar Alma Mekanizmasına Etkileri. Amme Ddaresi Dergisi, Cilt. 36 (2): 51-66.

Gul, S. (2009), Power and Power Relationships in the Public Policy Making Process. Turkish Public Administration Annual. Vol. 32-33: 1-15

Available at: http://works.bepress.com/skenangul/8/

Howes, M., Lyons, K., \& Bryant, S. (2004). Civil society Revisited: Possibilities for increasing community collaboration in a competitive world. Reference paper presented to the Australian Political Association Conference. University of Adelaide.

Hallacher, P. (2005). Why Policy Issue Networks Matter: The Advanced Technology Program and the Manufacturing Extension Partnership. New York: Rowman \& Littlefield

Inocencio, F. (2014). Reconceptualizing Sovereignty in the Post-National State: Statehood Attributes in the International Order. UK: The federal tradition, Author House. 
Jotterand, F., \& Dubljevic, V. (2016). Cognitive Enhancement: Ethical and Policy Implications in International Perspectives. New York: Oxford University Press.

Johnson, W. (2014). Public Administration: Partnership in Public Service ( $5^{\text {th }}$ ed.). Illinois: Waveland Press.

Leicht, K., \& Jenkins, C. (2009). Handbook of Politics: State and Society in Global Perspective. New York: Springer Science \& Business Media. Lynn, W. (Ed.). (2005). Legitimacy: Ambiguities of Political Success or Failure in East and Southeast Asia. USA: World Scientific.

Marmor, T. (2017). Comparative studies and the Drawing of Policy Lessons. Describing, Explaining, Evaluating, and Predicting. Journal of Comparative Policy Analysis. Research and Practices. 19:4, 313-326, DOI: 10.1080/13876988.2017.1279439

Millar, J. (Ed.). (2009). Understanding Social Security: Issues for Policy and Practice (2 ${ }^{\text {nd }}$ ed.). Bristol: Policy Press.

Reid, A., Hart, E., \& Peters, M. (Eds.). (2013). A companion to research in Education. New York: Springer Science \& Business Media.

Rochefort, D. \& Cobb, R. W. (Eds.). (1994). Problem Definition: An Emerging Perspective.” in The Politics of Problem Definition, Lawrence: Kansas University Press.

Robertson, G. (1978). Confidentiality in Government. An essay delivered at the Donald Gow Memorial Lecture, School of Public Administration, Queen's University, on 19 November. Published by Archival, Number 6 (Summer 1978).

Rechtschaffen, C, \& Gauna, E. (2002). Environmental justice: Law, Policy and Regulations, Durham, NC: Carolina Academic Press.

Todres, E. (1991). The Ethical Dimension of Public Service. Canadian Public Administration, 34 (1). https://doi.org/10.1111/j.1754-7121.1991. tb01429.x

Rubin, A., \& Babbie, R. (2009). Essential Research Methods for Social Work (2 ${ }^{\text {nd }}$ ed.). Australia: Cengage learning.

Russell, S. (1999). Conversion, Identity and Power: The impact of Christianity on Power Relationships and Social Exchanges. New York: University Press of America.

Ruch, C. (Ed.). (1991). The feasibility of vertical evaluation: Behavioral, Legal, Political, and Structural Considerations. Colorado: Institute of Behavioral science, University of Colorado.

Fischer, F., Miller, G., \& Sidney, M. (Eds.). (2007). Hand Book of Public Policy Analysis. Theory, Politics and Methods. London: CRC Press.

Scott, J. (Ed.). (1994). Power: Critical concepts, Volume 2. London: Routledge.

Zafarullah, H., \& Huque, A. (2013). Managing Development in a Globalised world: Concepts, Processes, and Institutions. London: CRC Press, Taylor \& Francis. 